\title{
Insulin resistance predicts the risk for recurrent coronary events in post-infarction patients
}

\author{
Barbara Szepietowska, Scott McNitt, Valentina Kutyifa, Dan Ryan, \\ James Corsetti, Charles Sparks, Arthur J. Moss, Wojciech Zareba
}

${ }^{1}$ Heart Research Follow up Program, University of Rochester Medical Center, Rochester, United States ${ }^{2}$ Department of Pathology and Laboratory Medicine, University of Rochester Medical Center,

Rochester, United States

\begin{abstract}
Background: We investigated the risk for recurrent coronary events associated with insulin resistance in post-infarction patients from the Thrombogenic Factors and Recurrent Coronary Events (THROMBO) study.

Methods: The association between insulin resistance expressed by Homeostatic Model Assessment 2 for Insulin Resistance (HOMA2-IR) and the risk for recurrent coronary events was investigated in a cohort of 1,032 patients evaluated 2 months after myocardial infarction (MI) with a follow-up of 26 months. The endpoint for the study was recurrent coronary event defined as cardiac death, nonfatal MI, or unstable angina, whichever occurred first. We used time dependent survival analysis and Cox proportional hazards regression method to determine the association between HOMA2 categorized as high $>75^{\text {th }}$ percentile and endpoints after adjustment for relevant clinical covariates and series of thrombogenic and dyslipogenic factors.

Results: High HOMA2-IR defined as in fourth quartile $(\geq 2.4)$ was associated with increased risk for recurrent coronary events (HR 1.44; CI 1.03-2.01; $p=0.03$ ) after adjustment for the clinical covariates: age, gender, diabetes, prior MI, pulmonary congestion, coronary artery bypass grafting and percutaneous transluminal coronary angioplasty. The highest risk of cardiac events was observed in non-obese patients (body mass index [BMI] $\leq 30 \mathrm{~kg} / \mathrm{m}^{2}$ ) with high HOMA2-IR (HR 1.5; CI 1.02-2.22; $p=0.038$ ). The plasma level of plasminogen activator inhibitor-1 was associated with higher risk for recurrent coronary events in patients with insulin resistance (HR 1.79; CI 1.05-3.03; $p=0.03$, interaction $p=0.018$ ).
\end{abstract}

Conclusions: In conclusion, insulin resistance predicts recurrence of coronary events in post-infarction population. HOMA2-IR is better than BMI in stratifying risk of recurrent coronary events. (Cardiol J 2015; 22, 5: 519-526)

Key words: insulin resistance, myocardial infarction, recurrent coronary events

\section{Introduction}

Insulin resistance (IR) plays a role in pathogenesis of metabolic syndrome and diabetes mellitus [1]. For evaluation of IR in larger clinical studies, the Homeostatic Model Assessment (HOMA) index is commonly used [2]. Previously, IR measured in patients with coronary artery disease was associated with increased risk for coronary events and predicted mortality independently from diabetes

Address for correspondence: Prof. Wojciech Zareba, Heart Research Follow-up Program, Cardiology Division, University of Rochester Medical Center; 265 Crittenden Blvd., PO Box 653, Rochester, NY 14642, USA, tel: 585-275-5391, fax: 585-273-5283; e-mail: wojciech.zareba@heart.rochester.edu 
mellitus [3, 4]. IR increased in-hospital mortality after acute coronary event $[5,6]$. The aim of the current study was to evaluate whether HOMA adds predictive value in the population after myocardial infarction (MI) in long-term follow-up and in a large study group. Identifying patients with IR with relation to their body mass index (BMI) may allow better risk stratification and initiation of aggressive risk factor modification after MI when lifestyle changes are more likely to be implemented [7].

\section{Methods}

\section{Study population}

This investigation is a sub-study of the Thrombogenic Factors and Recurrent Coronary Events (THROMBO) study. Detailed protocol and inclusion criteria have been previously described [8]. THROMBO was a multicenter study examining the effect of lipids and thrombogenic factors on recurrent coronary events, nonfatal MI or cardiac death during a 26-month follow-up in patients with index MI. Between October 11994 and June 301997 1,045 patients were enrolled and signed the consent for participation in a 2 -month post-infarction (baseline) visit. Glucose and insulin measurements were available for 1,032 of 1,045 patients $(98.7 \%)$ and constituted the study population of this report.

\section{Laboratory measurements}

Fasting blood samples were drawn 2 months after index MI. Insulin was measured by radioimmunoassay (coat-A-count diagnostic products). Plasma glucose was measured immediately after the blood was drawn by the enzymatic method using a glucose analyzer. HOMA2-IR was calculated using the online calculator downloaded from http:// www.dtu.ox.ac.uk. The BMI was calculated as body weight/height ${ }^{2}$ and expressed in kilograms per square meter $\left[\mathrm{kg} / \mathrm{m}^{2}\right]$. The hemostatic factor analyses included measurement of factor VII, factor VIIa, fibrinogen, von Willebrand factor, and plasminogen activator inhibitor-1 (PAI-1). Additionally, concentrations of apolipoprotein-B (apo-B), apolipoprotein A1, lipoprotein (A), cholesterol, high density lipoprotein and low density lipoprotein cholesterol, triglycerides and C-reactive protein (CRP) were measured.

\section{The endpoint}

The endpoint was defined as death due to coronary heart disease, recurrent nonfatal MI or unstable angina episode, whichever occurred first. Unstable angina definition included hospitalization during follow-up with an increase in either frequency or duration of angina symptoms, or development of new angina at rest - whichever occurred first with both requiring ischemic electrocardiogram (ECG) changes without enzyme elevation. A 2-member committee reviewed information on the endpoint events from appropriate medical records.

\section{Statistical analysis}

The effects of the HOMA2-IR by quartile on time to endpoint were examined graphically by the Kaplan-Meier method, and the log-rank statistic was used when comparing the difference in survival between each pair of curves. Nineteen patients who died of causes other than coronary heart disease were censored at the time of their death. The multivariate Cox proportional hazards regression analysis was performed with the Cox proportional regression hazards model (SAS PHREG computer program). The regression model was adjusted for factors that play a role in recurrent coronary events. To identify important clinical factors we included in the model previously pre-selected factors (age, sex, race, prior MI, prior stroke, history of diabetes mellitus, index infarct type by ECG [Q-wave vs. non-Q-wave], thrombolytic therapy, pulmonary congestion by chest roentgenogram, and ejection fraction during the index coronary event, and smoking status at enrollment) [8], and additionally we included factor identified by GRACE study (hypertension, coronary artery bypass grafting [CABG] and percutaneous transluminal coronary angioplasty [PTCA]) [9]. A significance level of $p=0.05$ was used for entering a variable into the basic clinical model. The following parameters enter clinical model: age, male, sex, diabetes mellitus, prior MI, pulmonary congestion on chest roentgenogram, PTCA and CABG. All probability values were 2 -tailed, and $\mathrm{p}<0.05$ was considered significant.

\section{Results}

A total of 1,032 patients were analyzed. The clinical characteristics of the entire study population and patients by HOMA2-IR status are presented in Table 1. Patients with high HOMA2-IR were more likely to be younger and less likely to be white, male, obese, male and with history of hypertension and diabetes. They were often treated with diuretics and angiotensin converting enzyme inhibitors. Patients categorized as having higher HOMA2-IR had higher BMI, fibrinogen, PAI-1, von Willebrand factor, apo-B, triglyceride and CRP. 
Table 1. Baseline characteristics according to Homeostatic Model Assessment 2 for Insulin Resistance (HOMA2-IR).

\begin{tabular}{|c|c|c|c|}
\hline Characteristics & All patients & HOMA2 01-3 & HOMA2 Q4 \\
\hline $\mathrm{N}$ & 1,032 & 774 & 258 \\
\hline \multicolumn{4}{|l|}{ Age: } \\
\hline Mean & $59 \pm 12$ & $59 \pm 12$ & $57 \pm 12^{*}$ \\
\hline$\geq 60$ years & $496(48 \%)$ & $383(44 \%)$ & $113(49 \%)^{*}$ \\
\hline Male & $774(75 \%)$ & $598(77 \%)$ & $181(70 \%)^{*}$ \\
\hline White & $770(75 \%)$ & $594(77 \%)$ & $176(68 \%)^{*}$ \\
\hline \multicolumn{4}{|l|}{ BMI $\left[\mathrm{kg} / \mathrm{m}^{2}\right]:$} \\
\hline Mean & $28 \pm 5.2$ & $27 \pm 4.7$ & $30 \pm 5.9 * *$ \\
\hline $\mathrm{BMI} \geq 30$ & $285(27 \%)$ & $177(23 \%)$ & $108(41 \%)^{*}$ \\
\hline \multicolumn{4}{|l|}{ History: } \\
\hline Prior myocardial infarction & $192(19 \%)$ & $140(18 \%)$ & $52(20 \%)$ \\
\hline Hypertension & $453(44 \%)$ & $319(41 \%)$ & $134(52 \%)^{*}$ \\
\hline Diabetes mellitus & $195(19 \%)$ & $90(12 \%)$ & $105(41 \%)^{*}$ \\
\hline Stroke & $29(3 \%)$ & $17(2 \%)$ & $12(5 \%)$ \\
\hline PTCA & $122(12 \%)$ & $92(12 \%)$ & $30(12 \%)$ \\
\hline CABG & $87(8.5 \%)$ & $59(11 \%)$ & $28(8 \%)$ \\
\hline Current cigarette smoker & $246(24 \%)$ & $172(22 \%)$ & $74(29 \%)$ \\
\hline Type of infarction new $\mathrm{Q}$ wave & $535(52 \%)$ & $390(50 \%)$ & $145(56 \%)$ \\
\hline Pulmonary congestion & $181(19 \%)$ & $121(16 \%)$ & $60(23 \%)^{*}$ \\
\hline \multicolumn{4}{|l|}{ Ejection fraction: } \\
\hline Mean & $47 \pm 12$ & $47 \pm 12$ & $47 \pm 12$ \\
\hline$<0.30$ & $113(11 \%)$ & $79(10 \%)$ & $34(13 \%)$ \\
\hline Thrombolytic therapy & $355(34 \%)$ & $269(35 \%)$ & $86(33 \%)$ \\
\hline \multicolumn{4}{|l|}{ Medication at enrolment: } \\
\hline Acetylsalicylic acid & $842(82 \%)$ & $630(81 \%)$ & $212(82 \%)$ \\
\hline ACE inhibitors & $384(37 \%)$ & $272(35 \%)$ & $112(43 \%)^{*}$ \\
\hline Beta-blockers & $783(76 \%)$ & $586(76 \%)$ & $197(76 \%)$ \\
\hline Calcium channel blockers & $210(20 \%)$ & $157(20 \%)$ & $53(21 \%)$ \\
\hline Diuretics & $172(17 \%)$ & $110(14 \%)$ & $62(24 \%)^{*}$ \\
\hline Statins & $342(33 \%)$ & $262(34 \%)$ & $83(32 \%)$ \\
\hline \multicolumn{4}{|l|}{ Hemostatic factors: } \\
\hline D-Dimer [ng/mL] & $521 \pm 638$ & $527 \pm 697$ & $509 \pm 422$ \\
\hline Factor VII [\%] & $103 \pm 43$ & $103 \pm 42$ & $103 \pm 45$ \\
\hline Factor VIla [ng/mL] & $2.5 \pm 1.7$ & $2.5 \pm 1.6$ & $2.6 \pm 1.8$ \\
\hline Fibrinogen [mg/dL] & $352 \pm 88$ & $346 \pm 82$ & $370 \pm 101^{*}$ \\
\hline Plasminogen activator inhibitor-1 [ng/mL] & $28 \pm 27$ & $24 \pm 22$ & $39 \pm 38^{* *}$ \\
\hline Von Willebrand factor [U/dL] & $149 \pm 68$ & $142 \pm 64$ & $168 \pm 76^{* *}$ \\
\hline Lipid and metabolic factors: & & $118 \pm 25$ & \\
\hline Apolipoprotein A1 [mg/mL] & $118 \pm 25$ & $121 \pm 27$ & $118 \pm 24$ \\
\hline Apolipoprotein B [mg/mL] & $123 \pm 28$ & $195 \pm 43$ & $126 \pm 29^{*}$ \\
\hline Cholesterol [mg/mL] & $197 \pm 44$ & & $201 \pm 43^{*}$ \\
\hline HDL-cholesterol [mg/mL] & $39 \pm 11$ & $39 \pm 11$ & $37 \pm 11^{*}$ \\
\hline LDL-cholesterol [mg/mL] & $120 \pm 38$ & $120 \pm 37$ & $119 \pm 39$ \\
\hline Lipoprotein(a) [mg/mL] & $24 \pm 23$ & $25 \pm 23$ & $22 \pm 21$ \\
\hline Triglyceride $[\mathrm{mg} / \mathrm{mL}]$ & $200 \pm 117$ & $187 \pm 102$ & $239 \pm 145^{* *}$ \\
\hline C-reactive protein [mg/L] & $0.49 \pm 0.7$ & $0.42 \pm 0.6^{*}$ & $0.7 \pm 1.0^{*}$ \\
\hline
\end{tabular}

Values are given as total number of patients and percentage or mean \pm standard deviation; ${ }^{*} p<0.05$ and ${ }^{* *} p<0.0001$ difference between patients with HOMA2-IR Q4 vs. Q1-3; ACE-inhibitors - angiotensin converting enzyme inhibitors; BMI — body mass index; CABG - coronary artery bypass graft surgery; PTCA - percutaneous transluminal coronary angioplasty 


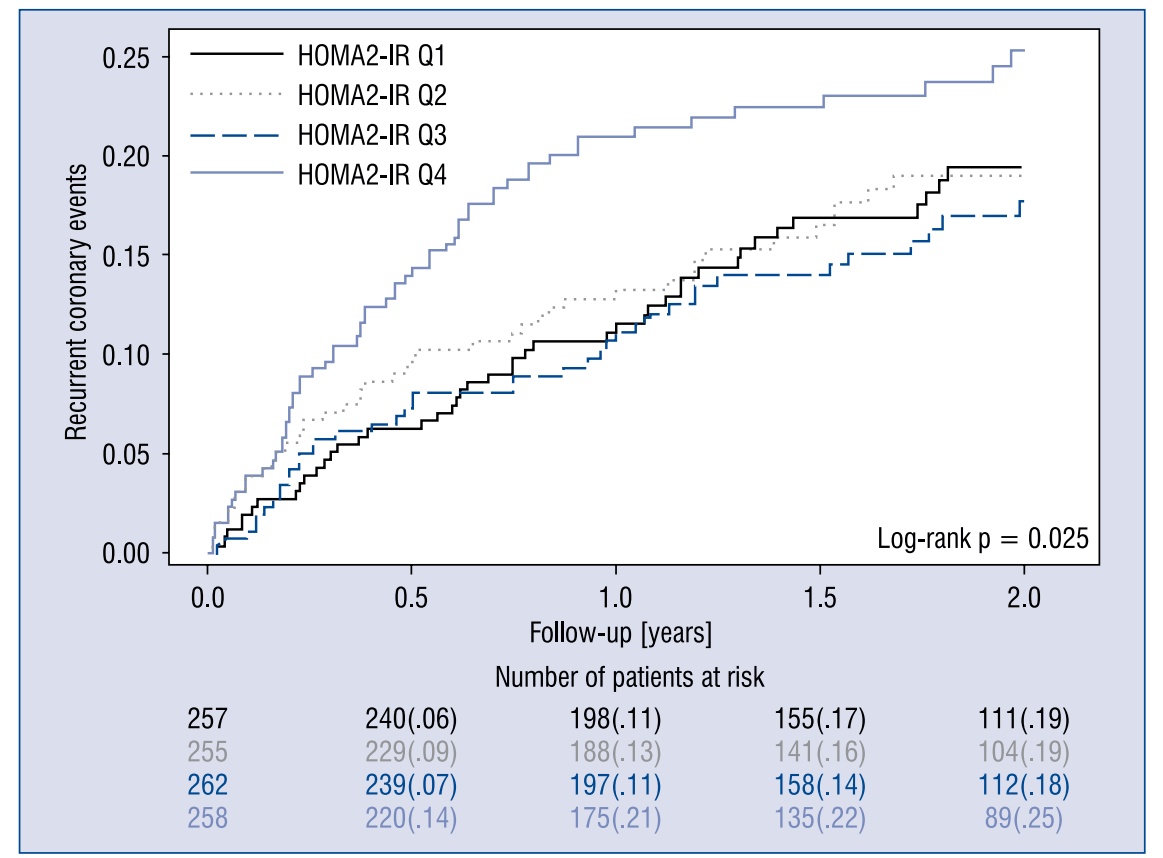

Figure 1. Cumulative probability of recurrent cardiac events in post-infarction patients by HOMA2-IR quartiles.

Table 2. The contribution of Homeostatic Model Assessment 2 for Insulin Resistance (HOMA2-IR) (Q4:Q1-3) to the risk of experiencing a recurrent cardiac event for patients in the top quartile $(\mathrm{Q} 4 \geq 2.4)$ compared to patients in the lower 3 quartiles.

\begin{tabular}{lcccc}
\hline & $\begin{array}{c}\text { Number of patients; } \\
\text { events }\end{array}$ & $\begin{array}{c}\text { Hazard } \\
\text { ratio }\end{array}$ & $\begin{array}{c}95 \% \text { confidence } \\
\text { interval }\end{array}$ & P \\
\hline $\begin{array}{l}\text { Recurrent coronary event (cardiac death or } \\
\text { myocardial infarction or unstable angina) }\end{array}$ & $933 ; 76$ & 1.44 & $1.03-2.01$ & $\mathbf{0 . 0 3 0}$ \\
Unstable angina & $933 ; 123$ & 1.51 & $1.02-2.25$ & $\mathbf{0 . 0 3 9}$ \\
Myocardial infarction & $933 ; 48$ & 1.19 & $0.63-2.26$ & 0.579 \\
Cardiac death & $933 ; 23$ & 1.34 & $0.55-3.27$ & 0.508 \\
\hline
\end{tabular}

The survival model includes adjustment for the following clinical variables: age, male sex, diabetes mellitus, prior myocardial infarction, pulmonary congestion on chest roentgenogram, percutaneous coronary intervention and coronary artery bypass grafting

The risk of recurrent cardiac events in patients with high HOMA2-IR

During a mean follow-up of $1.7 \pm 0.89$ years, the combined primary endpoint was met in $199 \mathrm{su}-$ bjects including: 127 patients with unstable angina, 52 patients with MI and 20 patients with cardiac death.

In Kaplan-Meier survival analysis, patients with highest HOMA2-IR quartile had a significantly higher probability of recurrent coronary events (log-rank, $\mathrm{p}=0.025$ ) (Fig. 1).

In the multivariate models after adjustment for age, gender, diabetes, prior MI, pulmonary congestion on chest roentgenogram, PTCA and
CABG patients with Q4: HOMA2-IR were at higher risk for recurrent coronary events (hazard ratio [HR] 1.44; confidence interval [CI] 1.03-2.01; $\mathrm{p}=0.03)$ compared to patients in the lower 3 quartiles (Table 2). When HOMA2-IR was analyzed separately for cardiac death, MI and unstable angina, only unstable angina was predicted with statistical significance (Table 2).

To examine whether the association between HOMA2-IR and clinical outcome was driven by a concurrent diagnosis of diabetes, we additionally analyzed interaction between diabetes status and HOMA2-IR that was not statistically different (interaction $\mathrm{p}=0.07$ ). 


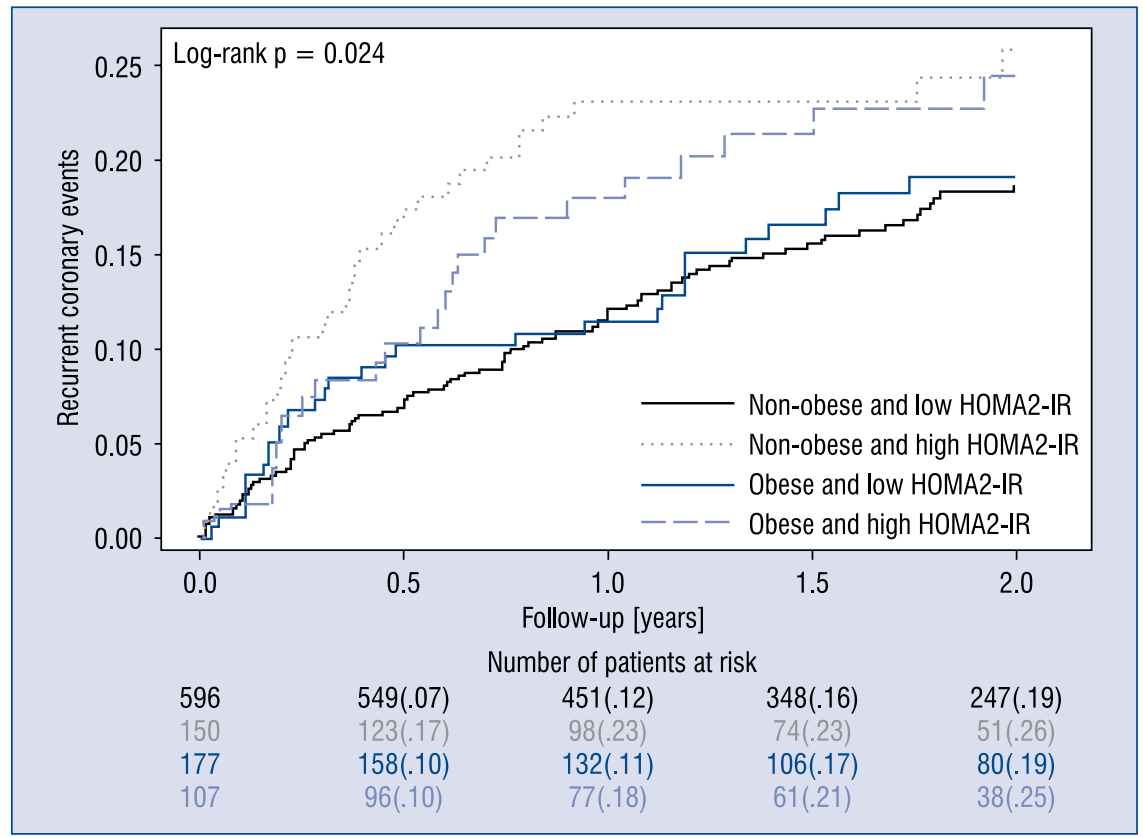

Figure 2. Cumulative probability of recurrent cardiac events in post-infarction patients with respect to body mass index and HOMA2-IR status. Gray line: non-obese with HOMA2-IR Q4, light blue: obese with HOMA2-IR Q4, blue: obese with HOMA2-IR Q3-O1 and black: non-obese with HOMA2-IR Q3-Q1.

Table 3. The contribution of Homeostatic Model Assessment 2 for Insulin Resistance (HOMA2-IR) (Q4:Q1-3) and obesity to the risk of experiencing a recurrent cardiac event. Reference group: non-obese with HOMA2-IR Q3-Q1, total: $\mathrm{n}=933$, number of events: 176.

\begin{tabular}{lccccc}
\hline & $\begin{array}{c}\text { Number of patients; } \\
\text { events }\end{array}$ & $\begin{array}{c}\text { Hazard } \\
\text { ratio }\end{array}$ & $\begin{array}{c}95 \% \text { confidence } \\
\text { interval }\end{array}$ & P \\
\hline $\begin{array}{l}\text { Reference group: non-obese and obese } \\
\text { with HOMA2-IR Q3-Q1 }\end{array}$ & $699 ; 118$ & & & & \\
Non-obese with HOMA2-IR Q4 & $136 ; 35$ & 1.50 & $1.02-2.22$ & $\mathbf{0 . 0 3 8}$ \\
Obese with HOMA2-IR Q4 & $98 ; 23$ & 1.34 & $0.84-2.16$ & 0.214 \\
\hline
\end{tabular}

The survival model includes adjustment for the following clinical variables: age, male, diabetes mellitus, prior myocardial infarction, pulmonary congestion on chest roentgenogram, percutaneous coronary intervention and coronary artery bypass grafting

\section{Clinical outcome of different metabolic groups as function of BMI and IR}

We assessed whether BMI status affects relationship between insulin sensitivity and risk for recurrent cardiac events. Kaplan-Meier survival analysis showed that non-obese patients with high HOMA2-IR had a significantly higher probability of recurrent coronary events (log-rank, $\mathrm{p}=0.024$ ). Non-obese and obese with low HOMA had a similarly low risk (Fig. 2).

In the multivariate models after adjustment for relevant clinical covariates, non-obese insulin resistance patients remained at highest risk for recurrent coronary event (HR 1.50; CI 1.02-2.22; $\mathrm{p}=0.038)($ Table 3$)$.
The contribution of thrombogenic and dyslipogenic factors for risk for recurrent coronary events

We evaluated if concomitant presence of highest risk quartile for evaluated thrombogenic and dyslipogenic factors and high HOMA2-IR will additionally incensed risk for recurrent coronary events. PAI-1 was associated with higher risk in patients with IR (HR 1.79; CI 1.05-3.03; $\mathrm{p}=0.03$, interaction $\mathrm{p}=0.018)$ (Table 4$)$.

\section{Discussion}

In primary risk stratification, IR predicts development of cardiovascular disease independently 
Table 4. The contribution of Homeostatic Model Assessment 2 for Insulin Resistance (HOMA2-IR) (Q4:Q1-3) and thrombogenic and dyslipogenic factors (Q4:Q1-3) to cardiac events.

\begin{tabular}{|c|c|c|c|c|c|}
\hline & \multicolumn{2}{|c|}{ HOMA2-IR Q4 } & \multicolumn{2}{|c|}{ HOMA2-IR Q1-3 } & \multirow{2}{*}{$\begin{array}{c}\text { Interaction } \\
\mathbf{P}\end{array}$} \\
\hline & $\begin{array}{l}\text { Hazard ratio } \\
\text { (95\% Cl) }\end{array}$ & $\mathbf{P}$ & $\begin{array}{l}\text { Hazard ratio } \\
\text { (95\% Cl) }\end{array}$ & $\mathbf{P}$ & \\
\hline $\begin{array}{l}\text { Plasminogen activator } \\
\text { inhibitor-1 } \mathrm{Q} 4\end{array}$ & $1.79(1.05-3.03)$ & 0.030 & $0.74(0.46-1.26)$ & 0.23 & 0.018 \\
\hline Apolipoprotein A1 Q1 & $2.5(1.4-4.45)$ & 0.001 & $1.23(0.78-1.94)$ & 0.37 & 0.055 \\
\hline Apolipoprotein B Q4 & $1.70(0.94-3.11)$ & 0.066 & $1.74(1.18-2.57)$ & 0.004 & 0.943 \\
\hline C-reactive protein $\mathrm{Q} 4$ & $1.76(1.00-3.11)$ & 0.050 & $1.33(0.05-2.07)$ & 0.2 & 0.435 \\
\hline HDL-cholesterol Q1 & $0.92(0.51-1.66)$ & 0.79 & $0.99(0.63-1.58)$ & 0.99 & 0.843 \\
\hline LDL-cholesterol Q4 & $1.37(0.75-2.5)$ & 0.29 & $1.27(0.85-1.92)$ & 0.23 & 0.843 \\
\hline Triglycerides Q4 & $0.89(0.51-0.54)$ & 0.69 & $0.8(0.5-1.28)$ & 0.35 & 0.761 \\
\hline Factor VIIa Q4 & $1.54(0.87-2.75)$ & 0.137 & $0.85(0.55-1.34)$ & 0.50 & 0.1139 \\
\hline Von Willebrand factor Q4 & $1.24(0.72-2.14)$ & 0.423 & $0.96(0.63-1.48)$ & 0.88 & 0.466 \\
\hline Fibrinogen Q4 & $1.1(0.73-1.67)$ & 0.375 & $1.07(0.62-1.85)$ & 0.78 & 0.929 \\
\hline
\end{tabular}

The survival model includes adjustment for the following clinical variables: age, male, diabetes mellitus, prior myocardial infarction, pulmonary congestion on chest roentgenogram, percutaneous coronary intervention and coronary artery bypass grafting

of diabetes mellitus [10-12]. In acute hospital setting, IR is associated with increased mortality after acute coronary event $[5,6]$. In our multicenter prospective study, IR predicts recurrence of coronary events in post-infarction population. Analysis of specific components suggested that the main effect was related to prediction of unstable angina. Our study is consistent with previous observations, furthermore emphases significance of IR in development of acute cardiac events in population at high cardiovascular risk. Importantly, IR was associated with adverse prognosis after adjustment for important clinical factors including diabetes mellitus.

IR was measured 2 months after MI and therefore it is less likely to be associated with adrenergic surge as a part of the acute stress responses, but rather a representation of metabolic disturbances. It has been postulated that IR in the post-myocardial period may predispose patients to micro vascular, myocardial injury and larger infract size [13]. Emerging evidence supports direct pro atherogenic effect of IR $[14,15]$, as well as its direct adverse effect on myocardial contractility [16].

An adipocentric view of the metabolic disturbances considers obesity the major clinical component for IR in peripheral metabolic tissues. However, the link between obesity and IR is complex, as indicated by the fact that some extremely obese people are glucose tolerant, while others with a mild degree of obesity develop severe IR and diabetes. In our study, patients identified as non-obese with IR had a higher risk for recurrent coronary events. Although obesity is an independent predictor of clinical coronary disease in the Framingham study [17], the association becomes weaker after adjustment for hypertension, hypercholesterolemia: features classically associated with obesity [18]. Noteworthy among people with established coronary artery disease is the fact that BMI is inversely associated with mortality, phenomenon known as "obesity paradox" in review [19]. It has been previously suggested that perhaps $\mathrm{BMI}$ is not a good parameter to explain the complex association of obesity and cardiovascular disease. Other parameters like visceral adiposity, body composition, waist circumference, body fat and free fat mass have a role in clinical practice [20]. Our study showed that HOMA2-IR is a better prognostic factor than BMI in predicting risk for recurrent coronary events suggesting that intracellular lipid accumulation in ectopic tissue triggers pathological responses with subsequent impairment in insulin signaling in review [21].

In our population, patients with higher HOMA2-IR index had higher level of von Willebrand factor, a marker of endothelial injury previously shown to be an independent risk factor for recurrent cardiac events in patients with diabetes [22]. Patients with higher HOMA2-IR had, similarly to patients with metabolic syndrome, higher level of apo-B, PAI-1 and triglyceride, but presence of metabolic syndrome in our population did not predict risk for recurrent coronary events [23]. In our study, patients 
with high HOMA2-IR and PAI-1 had increased risk for recurrent coronary events, but not patients with lower HOMA2-IR and high PAI-1 suggesting that presence of IR will modify risk associated with high PAI-1. The link between hypofibrinolysis and IR has been previously postulated [24, 25], but significance of PAI-1 is not limited to thrombolysis [26]. Elevated plasma level of PAI-1 has been shown to predict risk for recurrent coronary events and first MI [27, 28], but its predictivity is attenuated after adjustment for IR [29].

Currently there are no guidelines for the treatment of IR, especially in patients with cardiovascular risk [30]. It has been recognized that increased physical activity will improve insulin sensitivity [31]. For pharmacological intervention, metformin and insulin sensitizers for type 2 diabetes treatment [32] or antihypertensive and lipid lowering drugs can also improve insulin sensitivity [33].

\section{Conclusions}

Our findings indicate that IR is a good clinical marker of increased risk and improving insulin sensitivity may modify cardiovascular risk. HOMA2-IR is better than BMI in stratifying the risk of recurrent coronary events. Multilevel intervention to increase insulin sensitivity in people after MI may influence the clinical outcome.

\section{Acknowledgements}

This study was supported by research grant HL-48259 and HL-30616 from the National Institute of Health, Bethesda, MD. We would like to thank Patricia Severski from Heart Research Follow up Program for her assistance in data management and data analysis for THROMBO study and for this manuscript.

\section{Conflict of interest: None declared}

\section{References}

1. DeFronzo RA, Ferrannini E. Insulin resistance. A multifaceted syndrome responsible for NIDDM, obesity, hypertension, dyslipidemia, and atherosclerotic cardiovascular disease. Diabetes Care, 1991; 14: 173-194.

2. Wallace TM, Levy JC, Matthews DR. Use and abuse of HOMA modeling. Diabetes Care, 2004; 27: 1487-1495.

3. Ausk KJ, Boyko EJ, Ioannou GN. Insulin resistance predicts mortality in nondiabetic individuals in the U.S. Diabetes Care, 2010; 33: 1179-1185.

4. Kitta $\mathrm{Y}$, Nakamura T, Uematsu $\mathrm{M}$ et al. Insulin resistance negatively affects long-term outcome in non-diabetic patients with coronary artery disease after therapies to reduce atherosclerotic risk factors. J Cardiol, 2013; 62: 348-353.

5. Lazzeri $\mathrm{C}$, Valente $\mathrm{S}$, Chiostri $\mathrm{M}$, Attanà $\mathrm{P}$, Mattesini $\mathrm{A}$, Gensini GF. Acute insulin resistance assessed by the homeostatic model assessment in acute coronary syndromes without previously known diabetes. Angiology, 2014; 65: 519-524.

6. Sanjuan R, Blasco ML, Huerta R et al. Insulin resistance and short-term mortality in patients with acute myocardial infarction. Int J Cardiol, 2014; 172: e269-e270.

7. Fonarow GC, Gawlinski A, Moughrabi S, Tillisch JH. Improved treatment of coronary heart disease by implementation of a Cardiac Hospitalization Atherosclerosis Management Program (CHAMP). Am J Cardiol, 2001; 87: 819-822.

8. Moss AJ, Goldstein RE, Marder VJ et al. Thrombogenic factors and recurrent coronary events. Circulation, 1999; 99: 2517-2522 .

9. Eagle KA, Lim MJ, Dabbous OH et al.; GRACE Investigators. A validated prediction model for all forms of acute coronary syndrome: estimating the risk of 6 -month postdischarge death in an international registry. JAMA, 2004; 291: 2727-2733.

10. Hanley AJ, Williams K, Stern MP, Haffner SM. Homeostasis model assessment of insulin resistance in relation to the incidence of cardiovascular disease: The San Antonio Heart Study. Diabetes Care, 2002; 25: 1177-1184.

11. Hedblad B, Nilsson P, Engström G, Berglund G, Janzon L. Insulin resistance in non-diabetic subjects is associated with increased incidence of myocardial infarction and death. Diabet Med, 2002; 19: $470-475$.

12. Bonora $\mathrm{E}$, Kiechl $\mathrm{S}$, Willeit J et al. Insulin resistance as estimated by homeostasis model assessment predicts incident symptomatic cardiovascular disease in caucasian subjects from the general population: The Bruneck study. Diabetes Care, 2007; 30: 318-324.

13. Trifunovic D, Stankovic S, Sobic-Saranovic D et al. Acute insulin resistance in ST-segment elevation myocardial infarction in non-diabetic patients is associated with incomplete myocardial reperfusion and impaired coronary microcirculatory function. Cardiovasc Diabetol, 2014; 13: 73.

14. Reddy KJ, Singh M, Bangit JR, Batsell RR. The role of insulin resistance in the pathogenesis of atherosclerotic cardiovascular disease: an updated review. J Cardiovasc Med (Hagerstown), 2010; 11: 633-647.

15. Karrowni W, Li Y, Jones PG et al. Insulin resistance is associated with significant clinical atherosclerosis in nondiabetic patients with acute myocardial infarction. Arterioscler Thromb Vasc Biol, 2013; 33: 2245-2251.

16. Cadeddu C, Nocco S, Piano D et al. Early impairment of contractility reserve in patients with insulin resistance in comparison with healthy subjects. Cardiovasc Diabetol, 2013; 12: 66.

17. Hubert HB, Feinleib M, McNamara PM, Castelli WP. Obesity as an independent risk factor for cardiovascular disease: A 26-year follow-up of participants in the Framingham Heart Study. Circulation, 1983; 67: 968-977.

18. Bogers RP, Bemelmans WJ, Hoogenveen RT et al. Association of overweight with increased risk of coronary heart disease partly independent of blood pressure and cholesterol levels: A meta-analysis of 21 cohort studies including more than 300000 persons. Arch Intern Med, 2007; 167: 1720-1728.

19. De Schutter A, Lavie CJ, Milani RV. The impact of obesity on risk factors and prevalence and prognosis of coronary heart diseasethe obesity paradox. Prog Cardiovasc Dis, 2014; 56: 401-408. 
20. Bastien M, Poirier P, Lemieux I, Després JP. Overview of epidemiology and contribution of obesity to cardiovascular disease. Prog Cardiovasc Dis, 2014; 56: 369-381.

21. Samuel VT, Shulman GI. Mechanisms for insulin resistance: common threads and missing links. Cell, 2012; 148: 852-871.

22. Zareba W, Pancio G, Moss AJ et al. Increased level of von Willebrand factor is significantly and independently associated with diabetes in postinfarction patients. THROMBO Investigators. Thromb Haemost, 2001; 86: 791-799.

23. Corsetti JP, Zareba W, Moss AJ et al. Metabolic syndrome best defines the multivariate distribution of blood variables in postinfarction patients. Atherosclerosis, 2003; 171: 351-358.

24. Vague P, Raccah D, Scelles V. Hypofibrinolysis and the insulin resistance syndrome. Int J Obes Relat Metab Disord, 1995; 19 (Suppl. 1): S11-S15.

25. Juhan-Vague I, Alessi MC, Morange PE. Hypofibrinolysis and increased PAI-1 are linked to atherothrombosis via insulin resistance and obesity. Ann Med, 2000; 32 (Suppl. 1): 78-84.

26. Sobel BE, Woodcock-Mitchell J, Schneider DJ, Holt RE, Marutsuka K, Gold H. Increased plasminogen activator inhibitor type 1 in coronary artery atherectomy specimens from type 2 diabetic compared with nondiabetic patients: A potential factor predisposing to thrombosis and its persistence. Circulation, 1998; 97: 2213-2221.

27. Hamsten A, de Faire U, Walldius G et al. Plasminogen activator inhibitor in plasma: Risk factor for recurrent myocardial infarction. Lancet, 1987; 2: 3-9.
28. Thogersen AM, Jansson JH, Boman K et al. High plasminogen activator inhibitor and tissue plasminogen activator levels in plasma precede a first acute myocardial infarction in both men and women: Evidence for the fibrinolytic system as an independent primary risk factor. Circulation, 1998; 98: 2241-2247.

29. Juhan-Vague I, Pyke SD, Alessi MC, Jespersen J, Haverkate F, Thompson SG. Fibrinolytic factors and the risk of myocardial infarction or sudden death in patients with angina pectoris. ECAT Study Group. European Concerted Action on Thrombosis and Disabilities. Circulation, 1996; 94: 2057-2063.

30. Gibbons RJ, Abrams J, Chatterjee K et al. ACC/AHA 2002 guideline update for the management of patients with chronic stable angina - summary article: A report of the American College of Cardiology/American Heart Association Task Force on practice guidelines (Committee on the Management of Patients With Chronic Stable Angina). J Am Coll Cardiol, 2003; 41: 159-168.

31. Jennings G, Nelson L, Nestel P et al. The effects of changes in physical activity on major cardiovascular risk factors, hemodynamics, sympathetic function, and glucose utilization in man: A controlled study of four levels of activity. Circulation, 1986; 73: 30-40.

32. Kitabchi AE, Temprosa M, Knowler WC et al. Role of insulin secretion and sensitivity in the evolution of type 2 diabetes in the diabetes prevention program: effects of lifestyle intervention and metformin. Diabetes, 2005; 54: 2404-2414.

33. Ichikawa Y. Comparative effects of telmisartan and valsartan on insulin resistance in hypertensive patients with metabolic syndrome. Intern Med, 2007; 46: 1331-1336. 